\title{
Noradrenergic Pharmacotherapy, Intracerebral Infusion and Adrenal Transplantation Promote Functional Recovery After Cortical Damage
}

\author{
Dennis M. Feeney ${ }^{1,2}$, Michael P. Weisend ${ }^{1}$ and Anthony E. Kline ${ }^{1}$ \\ Departments of Psychology ${ }^{1}$ and Physiology ${ }^{2}$, Logan Hall, The University of New Mexico \\ Albuquerque, NM 87131, USA
}

\begin{abstract}
The research described in this review briefly summarizes evidence that short term pharmacological enhancement of noradrenergic (NA) synaptic activity, combined with symptom relevant experience (SRE), promotes functional recovery of some symptoms of cortical damage in rat, cat and human beings even when treatment is initiated from days to weeks after injury. A summary is provided of the numerous drugs tested in rodent cortical injury models which have been proven useful for predicting beneficial or harmful effects on behavioral outcome in human stroke. The pattern of drug effects indicates a central role for $\mathrm{NA}$ in functional recovery. Additionally, studies of the effects of direct intraventricular infusion of monoamine neurotransmitters are reviewed and further support the hypothesized role of NA in recovery from some symptoms of cortical injury. The site of NA/SRE interaction to promote recovery from hemiplegia apparently involves the cerebellar hemisphere contralateral to the cortical injury. Microinfusions of NA into the contra- but not ipsilateral cerebellar hemisphere dramatically enhance recovery. Furthermore, like its systemic action, microinfusion of the $\alpha_{1}$ NA receptor antagonist, phenoxybenzamine, reinstates hemiplegia. A "permanent" symptom of motor cortex injury in the cat is the complete loss of tactile placing contralateral to the injury which does not spontaneously recover for as long as seven years after ablation. This postural reflex is temporarily restored for 8-12 hours following amphetamine administration. However, this permanently lost reflex can be enduringly restored by transplanting
\end{abstract}

catecholamine secreting adrenal tissue into the wound cavity. The experiment is reviewed in detail and involves chromaffin cell autografts into the frontal cortex ablation wound cavity producing a restoration of tactile placing for the 7-10 month duration of the study. This enduring restoration of tactile placing is considered a result of the release of catecholamines into the CNS from the grafted chromaffin cells found, by histochemical methods, surviving 7-10 months after transplant. Lastly, we attribute these delayed treatment effects to an attenuation of a diaschisis, or remote functional depression, in morphologically intact areas anatomically connected to the area of injury. The widespread reduction of glycolytic and oxidative metabolism, produced by focal cortical injury, is normalized by the same treatment which alleviates symptoms and is worsened by drugs which exacerbate deficits. These data support the hypothesis that providing SRE during a period of enhanced NA synaptic activity produces an enduring functional recovery after cortical injury by attenuating remote functional depression. This treatment for enhancing recovery is especially attractive since it is effective even when begun weeks after cortical damage.

\section{KEY WORDS}

traumatic brain injury, stroke, functional recovery, "soft excitotoxicity hypothesis", diaschisis, adrenal grafting 


\section{INTRODUCTION}

Brain damage resulting from stroke or traumatic brain injury (TBI) produces significant, and too often permanent,, impairment of physical, and/or cognitive abilities in approximately 800,000 individuals in the U.S. alone each year $/ 39,58 /$. There are approximately 300,000 reported cases of first stroke $/ 54 /$, and while most patients show some recovery, stroke accounts for almost half the hospitalizations for neurological disability /41/ and is the cause of more than $10 \%$ of all deaths $/ 66 /$. Some consider TBI to be a more devastating brain injury than stroke because it primarily affects a younger population, requiring a more prolonged period of expensive medical care and loss of productive years. The incidence of major head injury for the 17-44 age group in this country rose from 351,000 in $1972-73$ to 609,000 in $1974-75$ $/ 14 /$. Of the more than 300,000 permanently disabled Americans each year due to trauma, neurological deficits account for most of the deficits $165 /$.

The true cost of severe TBI is incalculable. The medical and rehabilitation efforts to help TBI cases are prolonged, labor intensive and astronomically expensive. The direct hospitalization costs for severe head trauma cases have been calculated at two trauma centers in Maryland at $\$ 105,350$ per case for one year. When the authors extrapolated the data to the 16-45 year age group for patients for one year and only in the state of Maryland for 1983 the cost was estimated at 29 million dollars /48/. Clearly, brain damage, a serious, survivable injury, is a major medical problem and has no acknowledged treatment $/ 24,25 /$.

The dominant theme of current research on therapy for brain damage has focused on very early interventions to limit the spread of "secondary" injury, such as attenuating excitotoxicity, initiated by the initial insult $/ 1,57 /$. These important research efforts are likely to result in increased survival of brain injured individuals, some perhaps with lessened deficits if treatment is initiated in the first hours after a stroke or TBI. Such patients will still have persisting disabilities and unfortunately many will be reached too late for these potential injurylimiting therapies to be effective. The research presented in this review describes an experimental therapeutic regimen that can be initiated relatively long after cortical injury has occurred. An accelerated rate of recovery to higher functional levels can be achieved after a short treatment period beginning 1 day after injury in the rat and 10 days after injury in the cat.

\section{AMPHETAMINE PLUS EXPERIENCE PROMOTES FUNCTIONAL RECOVERY}

To our knowledge, the first observation that Damphetamine (AMPH) could enhance function lost after brain injury, albeit transiently, was reported by Maling and Acheson in 1946 /49/. They reported that AMPH administration restored righting, hind limb stepping, tactile and proprioceptive placing reflexes for up to 9 hours in low decerebrate cats. There have been some follow-up laboratory investigations. These studies confirmed the original observations on postural reflexes using animals with different lesions or using related drugs. Our laboratory and others have reported that AMPH also ameliorates the cortical injury-induced symptoms involving more complex behaviors, ranging from locomotion to visually guided behavior, to learning and memory $/ 2,6,18,21$ $23,28,33,37,38,40,42,50,53,62,64 /$. (However, this effect on learning and memory has not been systematically studied.) Neglect of the intriguing early observations that amphetamine could enhance functional recovery after brain injury may be attributable to several factors: 1) The drug effects were on postural reflexes, behaviors seemingly remote from clinical problems; 2) The restoration of reflexes was "drug dependent", only lasting during the period of drug action; 3) The Zeitgeist that brain injury was only manageable and not amenable to treatment.

Interest in a potential pharmacotherapy for brain injury began in the 1980 s based on two developments. First, a wide acceptance of the "excitotoxicity" concept, which suggested the usefulness of pharmacological treatment within the first hours after brain injury $/ 1,57 /$. Second, accumulating literature which indicated enhanced functional recovery by short-term administration of AMPH combined with SRE even when initiated days or weeks following brain injury (for reviews 
see $/ 19,24,25 /$ ). This latter development, which is the focus of this review, originated with the 1982 Feeney et al. $/ 21 /$ report that a single administration of AMPH $(2.0 \mathrm{mg} / \mathrm{kg}$ i.p., a low dose in rat, producing few sterotypies or piloerection and only mild anorexia for about 6 hours) administered 24 hours after unilateral ablation of the sensorimotor cortex (SMCX) combined with SRE in rats produced an enduring accelerated recovery from hemiplegia measured by beam-walking (BW) agility. This ablation model has been suggested to be an animal model for functional recovery after stroke $135 /$.

Subsequently, Hovda and Feeney /37/ described a similar enhancement of recovery from hemiplegia measured by BW in the hemiplegic cat when AMPH treatment was not initiated until 10 days after unilateral frontal cortex ablation. Of great significance was the fact that the enhanced recovery was not simply a transient pharmacological effect but endured long after any direct drug effect had dissipated. Treated cats were fully recovered on the BW test by 21 days after injury and maintained the recovery from hemiplegia, whereas control animals had not recovered in 60 days when the experiment was terminated. This treatment effect was even more dramatic in cats with large bilateral frontal ablations $/ 62 /$. These severely disabled animals required three treatments spaced at four day intervals to achieve recovery whereas the control group showed little improvement.

In a rat model of stroke $/ 55 /$ homologous blood clots were used as emboli. These emboli occlude the end arterioles of the middle cerebral artery causing seizures, death (40\% mortality), weight loss and a very severe and enduring locomotor disability. These marked deficits were not improved by a single administration of AMPH but required multiple AMPH administrations or a short-term, very low dose continuous infusion of AMPH (by osmotic minipump, s.c., $1 \mathrm{mg} / \mathrm{kg} /$ day) for 7 days to enhance recovery. This dose of AMPH infusion produced no anorexia in normal rats and, paradoxically, treated stroke rats lost less body weight than saline controls and had fully recovered locomotor agility while the control animals had severe locomotor disabilities 30 days post infarct.

In studies of TBI, the severity of disability has been shown to be an important factor in determining effects on recovery from hemiplegia $/ 4 /$. In a rat focal impact trauma model to produce SMCX TBI /20/, AMPH/SRE was found to enhance BW recovery $/ 25 /$. Traumatic cortical injury apparently requires a slightly higher dosage to promote recovery, as has been reported for stroke models $138,55 /$. The hemisphere injured also appears to alter the dose response curve $/ 43 /$.

Moreover, the AMPH/SRE effects on functional recovery are likely to be different in males and females. Female cats have been studied in every ablation study from this laboratory using that species. But the number of cats has been too small to indicate subtle gender differences such as requiring different dosages. As only male rats have been studied in the ablation and trauma models, clearly females must also be investigated; because of their short estrous cycle, four days, this would have to be monitored to clearly interpret gender differences in effects on outcome measures.

The most important factor modifying the effect of AMPH on functional recovery is the experience the animal receives during the period of apparent drug action. In the hemiplegic rat and cat SRE (e.g. BW trials) must be provided during the period of drug action for any facilitation of locomotor recovery. If the rats are confined to a small cage to prevent major ballistic movements, AMPH alone given at 24 hours post SMCX ablation produces no facilitation of recovery from hemiplegia $/ 21 /$. In an experiment using hemiplegic cats two groups were given the same AMPH dose and the same number of BW trials. One group received the SRE immediately prior to and the other group after a single AMPH administration; only the latter group had a facilitated locomotor recovery /37/.

In the motor system one cannot truly control the animals' experience. One can only allow or prod the animal into making the desired movements. However, in experiments on vision, the experimenter has complete control over SRE, since turning off the lights prevents any visual experience. This was utilized to carefully study the generality of the necessity of SRE during the time of AMPH action for promoting functional recovery after cortical injury. The experiment was conducted studying binocular depth perception, measured by visual cliff performance, a "function" which is permanently and completely lost after bilateral 
ablation of cortical areas 17 , especially its mesial face, and 18 in the cat $/ 23 /$. This profound and "permanent" deficit can be enduringly restored after four doses of AMPH, but only if the animals are kept in the light after amphetamine administration, i.e. given SRE during the period of drug action. Even after seven doses of AMPH there is no recovery if the animals are housed in darkness for eight hours after each drug administration.

In addition to indicating the necessity of SRE during the first hours after AMPH administration, these findings have four other important implications: 1) The AMPH/SRE therapy for brain injury can be utilized to treat qualitatively different deficits after injury to different cortical areas. The AMPH/SRE promotes recovery of binocular depth perception and hemiplegia following unilateral frontal cortex or posterior cortical injuries respectively. 2) The AMPH/SRE is effective in enhancing recovery after bilateral $/ 23,62 /$ or unilateral injury. This indicates that the mechanism(s) mediating this recovery does not involve the contralateral homologous cortex. As the locus coeruleus and cerebellum have been hypothesized /19,24-26/ to mediate hemiplegia recovery, histochemical studies implicate the superior colliculus to be additionally involved in recovery of binocular depth perception (See /19/ for a discussion and description of a confirmation experiment). Histochemical measurements of oxidative metabolism implicate alleviation of depressed collicular activity as a basis for this remarkable recovery /19/. 3) This experiment most clearly indicates that AMPH/SRE therapy does much more for brain injury than just accelerate recovery. The loss of depth perception after bilateral visual cortex ablation, if untreated, would never recover. 4) For short-term AMPH/SRE to be effective after bilateral visual cortex ablation, treatment can be initiated 10 days after brain injury but treatment started later than the 3rd month after injury was ineffective $/ 23 /$. Importantly, this therapy appears to have a long therapeutic time window.

Amphetamine administration combined with SRE does not enhance performance on all sensorymotor tasks after SMCX injury. For example, after SMCX TBI the recovery of fine motor coordination, measured by forepaw grasping ability, is not significantly altered, even by multiple treatments, even though BW recovery is enhanced in the same animals $/ 24,25 /$. Moreover, AMPH retards BW recovery after cerebellar lesions $19 /$. Clearly, the indications and contraindications of AMPH/SRE should be delineated.

\section{EVALUATION OF OTHER DRUGS}

We hypothesized that increased NA activity is involved in the effects of AMPH/SRE on recovery after cortical injury. However, AMPH has effects on many neurotransmitter systems in addition to NA. In the normal rat, AMPH dramatically increases the release of NA $/ 3,5,30,45-47,52,56 /$, dopamine (DA) $13,15,30,51,56 /$, gammaaminobutyric acid $/ 5,15 /$, acetylcholine $/ 5,15 /$, and serotonin $/ 3,15,30,59 /$. However, many studies have been conducted in this laboratory and in others to determine which one or more of the neurotransmitters released by AMPH is critical for the AMPH/SRE facilitation of recovery after cortical injury. For example, using the same paradigm, a single dose of the AMPH analogues, and catecholamine agonists, phentermine and phenylpropanolamine $/ 24,25$ /, given 24 hours after SMCX ablation in rat, both produce enduring $\mathrm{BW}$ recovery. However, a single dose of methylphenidate, a stimulant which blocks catecholamine reuptake, unlike AMPH which primarily produces transmitter release, did not facilitate BW recovery using our standard BW rat regimen. However, in further studies a significant and enduring enhancement of BW agility was produced by a single dose of methylphenidate when the number of BW trials was increased early after drug administration /42/. This drug presumably required more early BW experience because of its shorter half-life compared to AMPH. It is now clear that these pharmacological effects of NA/SRE on functional recovery are not attributable to the stimulant properties of these drugs but to the increased NA activity they produce. Specifically, it has recently been shown that the antidepressant desiprimine, which lacks stimulant properties but does block NA reuptake, also facilitates recovery from hemiplegia in the rat ablation model /11/.

A pharmacological strategy to analyze the neurotransmitter system(s) involved in the 
AMPH/SRE effect is to administer specific receptor agonists and antagonists using the same model and test paradigm that clearly demonstrated the AMPH and related drug effects on BW recovery $/ 19,24,25$, $29,60,61 \%$. The data from these studies using ablation are summarized in Table 1 . The results using the same test after TBI are summarized in Table 2. All experiments listed used our conservative test to assess drug effects on BW recovery. At 24 hours after SMCX ablation rats were given a single dose of the test drug and $\mathrm{BW}$ recovery evaluated for several days to several weeks depending upon the laboratory conducting the experiment. We consider this to be a conservative screening test since any effects on BW recovery are only evaluated following a single dose administered 24 hours after SMCX injury. The experiments involving cats all used large frontal cortex ablations to produce hemiplegia or bilateral visual cortex ablations to produce depth perception deficits and treatment was initiated 10 days after surgery. In the cat, three AMPH/SRE treatments at 4-day intervals were conducted.

The data summarized in Tables 1 and 2 indicate

TABLE 1

Drugs tested for effects on recovery of function after cortical ablations

Catecholamine agonists

D-Amphetamine (rat: /18,21,33/; cat: /22,23,62/)

Monoamine agonist

0.5 or $1 \mathrm{mg} / \mathrm{kg}$, no significant (NS) effects;

2 and $4 \mathrm{mg} / \mathrm{kg}$, significant facilitation motor and vision

\section{Methylphenidate /42/}

Catecholamine agonist

$10 \mathrm{mg} / \mathrm{kg}$, significant facilitation with multiple or repeated doses

Phenylpropanolamine /25/

Catecholamine agonist

$10 \mathrm{mg} / \mathrm{kg}$, NS effects;

15 and $20 \mathrm{mg} / \mathrm{kg}$, significant facilitation

Phentermine /25/

Catecholamine agonist

6 or $24 \mathrm{mg} / \mathrm{kg}$, NS effects;

$12 \mathrm{mg} / \mathrm{kg}$, significant facilitation

\section{Catecholamine antagonists \\ Haloperidol /24,25,29,60/ \\ Catecholamine antagonist \\ $0.4 \mathrm{mg} / \mathrm{kg}$, blocks AMPH facilitation, retards spontaneous recovery}

\section{Reuptake blockers \\ Desipramine /11/ \\ Inhibits NA reuptake \\ 6 and $19 \mathrm{mg} / \mathrm{kg}$, significant facilitation \\ Trazodone /11/ \\ Inhibits 5-HT reuptake \\ 6 and $12.5 \mathrm{mg} / \mathrm{kg}$, significant facilitation}

\author{
Specific receptor agonists \\ Phenylephrine /61/ \\ NA $\alpha_{1}$ receptor agonist \\ 2,4 , or $8 \mathrm{mg} / \mathrm{kg}$, NS effects \\ Prazosin /61/ \\ NA $\alpha_{1}$ receptor antagonist \\ 2 or $4 \mathrm{mg} / \mathrm{kg}$, NS effects \\ Clonidine /34/ \\ $\mathrm{NA} \alpha_{2}$ receptor agonist \\ $0.02,0.06$, and $0.2 \mathrm{mg} / \mathrm{kg}$, significant retardation of \\ recovery (However see /60/, NS effects)
}

Yohimbine /61/

NA $\alpha_{2}$ receptor antagonist

0.5 or $5 \mathrm{mg} / \mathrm{kg}$, NS effects;

$10 \mathrm{mg} / \mathrm{kg}$, significant facilitation

Idazoxan $/ 24,25,35 /$

$\mathrm{NA} \alpha_{2}$ receptor antagonist

$1.0 \mathrm{mg} / \mathrm{kg}$, NS effects;

$2.0 \mathrm{mg} / \mathrm{kg}$, significant facilitation

Apomorphine /22/

Dopamine receptor agonist

$0.5 \mathrm{mg} / \mathrm{kg}$ transient, weak restoration of tactile placing in cat;

0.2 to $20 \mathrm{mg} / \mathrm{kg}$, NS effects in rat (unpublished data)
Methoxamine (unpublished data)
NA $\alpha_{1}$ receptor agonist
8 or $10 \mathrm{mg} / \mathrm{kg}$, NS effects

MK-801/32/

NMDA antagonist and NA reuptake blocker

$0.5,1,2 \mathrm{mg} / \mathrm{kg}$, NS effects 
an important role for $\alpha_{1}$-NA receptors in enhancing functional recovery after cortical injury. Administration of the $\alpha_{1}$-NA receptor antagonist, phenoxybenzamine, in combination with AMPH blocked the beneficial effect of AMPH/SRE on recovery after embolic stroke $/ 55 /$. To investigate this issue further a variety of $\alpha_{1}$-NA agonists and antagonists were examined for their effects on recovery of function. The $\alpha_{1}$-NA receptor agonists phenylephrine and methoxamine had no significant facilitatory effects on recovery of BW ability following SMCX injury $/ 24,25,29 /$. In addition, the $\alpha_{1}$-NA antagonist prazosin was administered to animals after SMCX contusion or ablation. Prazosin had no detrimental effect in ablated animals but retarded recovery in animals with contusion (see Tables 1 and 2). To account for some of the differences on BW recovery in response to a single drug dose, a most conservative treatment, it appeared that recovery in animals with TBI was more readily disrupted than in animals with ablation and facilitation of recovery was less readily produced than after ablation. This may be a result of the TBI producing selective neuronal death in subcortical areas in addition to SMCX injury $/ 28 /$. The pattern of results provides behavioral pharmacology data indicating a central role for NA in recovery after both types of cortical injury. Drugs which directly or indirectly increased $\alpha_{1}$-NA activity promoted BW recovery whereas $\alpha_{1}$-NA receptor antagonists slowed recovery from hemiplegia. A theoretical problem is that while selective $\alpha_{1}$-NA antagonists alone slow recovery $\alpha_{1}$ agonists do not facilitate recovery. This issue is discussed in detail elsewhere $/ 29 /$. It was concluded that disruption of the recovery process is less complicated than its facilitation. While retardation of recovery can be produced by blocking one receptor, selective $\alpha_{1}$-NA activation by an agonist alone is insufficient to "enable" SRE to produce an enduring enhancement.

As has been reviewed elsewhere $119,31,60 /$, the results from preliminary human studies are strikingly parallel to BW recovery data in non-human animals. Statistically significant facilitation of recovery from hemiplegia /16/ and aphasia /67/ has been reported in double blind studies. Obtaining significant results with 4-5 patients in a group suggests that the
TABLE 2

Drugs tested for effects on recovery of function after cortical trauma

\section{Catecholamine agonists \\ Amphetamine /25,64/ \\ Monoamine agonist \\ $2 \mathrm{mg} / \mathrm{kg}$, significant facilitation}

\section{Catecholamine antagonists}

Haloperidol /29/

Catecholamine antagonist

$0.4 \mathrm{mg} / \mathrm{kg}$, blocks AMPH facilitation and retards recovery

\author{
Non-catecholamine agonists \\ Morphine (unpublished data) \\ Opiate receptor agonist \\ 5 or $20 \mathrm{mg} / \mathrm{kg}$, NS effects \\ $10 \mathrm{mg} / \mathrm{kg}$, disability specific facilitation
}

\section{Specific receptor agonists \\ Methoxamine /29/ \\ NA $\alpha_{1}$ receptor agonist \\ 1,4 or $8 \mathrm{mg} / \mathrm{kg}$, NS effects}

Prazosin /29/

NA $\alpha_{1}$ receptor antagonist

$4 \mathrm{mg} / \mathrm{kg}$, significant retardation

Yohimbine /4/

NA $\alpha_{2}$ receptor antagonist

$10 \mathrm{mg} / \mathrm{kg}$, disability specific facilitation

Propranolol /29/

NA $\beta_{1}$ and $\beta_{2}$ receptor antagonist

$10 \mathrm{mg} / \mathrm{kg}$, NS effects

Drugs tested for effects on recovery of function in animal models of stroke*

D-Amphetamine /17,55/

monoamine agonist

embolic stroke model: NS effect with single administration, significant reduction in morbidity and mortality with continuous infusion of low dose $1 \mathrm{mg} / \mathrm{kg} /$ day, or multiple doses, $2 \mathrm{mg} / \mathrm{kg}$ (effects blocked by phenoxybenzamine)

photochemically-induced focal cortical infarct: significant enhancement of sensorimotor performance and reversal of glucose hypometabolism, $4 \mathrm{mg} / \mathrm{kg}$, i.v.

*See /35/ for discussion of ablation/hemiplegia model's relevance for functional recovery after stroke. 
AMPH/SRE effect may be very robust. Also similar to the observations in laboratory studies is that the same or similarly acting drugs slow recovery from hemiplegia after a stroke. A retrospective study /31/ compared the recovery rate for two groups of patients and found that for those given drugs shown to slow BW recovery after SMCX ablation in rat, recovery was also slowed after stroke. This retrospective but double blind study used the same outcome measure as the AMPH/SRE stroke studies.

As summarized in Table $3, \alpha_{1}$-NA antagonists dramatically reinstate SMCX symptoms for several hours in apparently recovered animals at a dose having no effect on BW in normal animals. The $\alpha_{1-}$ NA antagonists, prazosin and phenoxybenzamine, reinstate BW deficits in both contused and ablated animals following complete recovery of beamwalking ability. The reinstatement is unlikely to be due to a non-specific drug effect since the deficits reappear only in the limbs contralateral to the cortical injury, and do not occur after a sedating dose of pentobarbital $/ 24,25 /$. Taken together these data indicate that activity at the $\alpha_{1}$-NA receptor is important for both facilitation and maintenance of recovery from hemiplegia. However, NA is an important but not a necessary condition since spontaneous recovery still occurs after destruction of the forebrain NA innervation from the locus coeruleus /8/. Additionally, increased activity at the $\alpha_{1}$-NA receptor site alone is not sufficient to produce an enhancement of BW recovery. An interaction between NA and the neural activity of SRE in the cerebellum has been proposed to account for the AMPH/SRE facilitation of recovery from hemiplegia /19/. The effect of NA is considered "enabling or permissive" for the enduring alterations produced by SRE /19/.

TABLE 3

Drugs tested for reinstatement of symptoms in animals recovered from SMCX injury

\author{
Ablation model \\ Prazosin /61/ \\ NA $\alpha_{1}$ receptor antagonist \\ 2 or $4 \mathrm{mg} / \mathrm{kg}$, significant reinstatement \\ Phenoxybenzamine /25/ \\ NA $\alpha_{1}$ receptor antagonist \\ $10 \mathrm{mg} / \mathrm{kg}$, significant reinstatement \\ Clonidine $/ 34,60,61 /$ \\ $\mathrm{NA} \alpha_{2}$ receptor agonist \\ 0.1 or $0.4 \mathrm{mg} / \mathrm{kg}$, significant reinstatement, rat and cat
}

Yohimbine /61/

NA $\alpha_{2}$ receptor antagonist

$0.5,5$ or $10 \mathrm{mg} / \mathrm{kg}$, NS effects
Propranolol /61/
NA $\beta_{1}$ and $\beta_{2}$ receptor antagonist
$20 \mathrm{mg} / \mathrm{kg}$, NS effects

Pentobarbital /19, p. 121/

Affects many systems

$5 \mathrm{mg} / \mathrm{kg}$, for 5 days, NS effects

MK-801 /32/

NMDA antagonist and NA reuptake blocker

$0.5 \mathrm{mg} / \mathrm{kg}$, NS effects

\author{
Contusion model \\ Prazosin /29/ \\ NA $\alpha_{1}$ receptor antagonist \\ $4 \mathrm{mg} / \mathrm{kg}$, significant reinstatement \\ Phenoxybenzamine /29/ \\ NA $\alpha_{1}$ receptor antagonist \\ $10 \mathrm{mg} / \mathrm{kg}$, significant reinstatement \\ Clonidine /29/ \\ NA $\alpha_{2}$ receptor agonist \\ $0.4 \mathrm{mg} / \mathrm{kg}$, significant reinstatement
}

\author{
Propranolol /29/ \\ NA $\beta_{1}$ and $\beta_{2}$ receptor antagonist \\ $10 \mathrm{mg} / \mathrm{kg}$, NS effects
}
Haloperidol /29/
Catecholamine antagonist
$0.4 \mathrm{mg} / \mathrm{kg}$, significant reinstatement effects only with chronic administration


Activity at other NA receptors, which can indirectly affect activity at $\alpha_{1}$-NA receptors, is also important in recovery from hemiplegia. The commonly prescribed antihypertensive clonidine, an $\alpha_{2}$-NA agonist which decreases $\mathrm{NE}$ release by activating the NA neurons' autoreceptors, retards BW recovery after SMCX ablation in the rat $/ 34 /$, but this finding was not replicated in another study using the identical model $/ 61 /$. The only important procedural difference was the use of additional motivation consisting of occasional "prodding". Furthermore, the $\alpha_{2}$-NA antagonists, yohimbine /4,61/ and idazoxan /35/, which increase NA release, both facilitate BW recovery after rat SMCX ablation, similar to AMPH. Like agents that antagonize $\alpha_{1}$-NA receptors, drugs which act at $\alpha_{2}$ NA receptors can also affect the maintenance of functional recovery. The $\alpha_{2}$-NA agonist clonidine reinstates BW deficits following recovery from TBI or ablation $/ 25,29,61 /$, an effect that is quite striking in the recovered cat.

There is a very important clinical relevance of these data. After patients are admitted to a hospital for stroke their blood pressure medication is frequently changed to clonidine. Given its adverse affects on BW recovery in rat and cat and its apparent negative effect on recovery from hemiplegia in stroke patients, clonidine and other drugs reducing $\alpha_{1}$-NA transmission should not be administered early after stroke $/ 31 /$.

\section{INTRACEREBRAL MONOAMINE INFUSION}

To further characterize the transmitter(s) mediating the AMPH/SRE actions on recovery of function, studies using intraventricular infusions of the monoamine neurotransmitters with appropriate SRE were conducted. The results of these studies showed that the infusion of NA, but not DA or 5HT (serotonin), mimicked the effects of the AMPH/SRE on BW recovery /10 and unpublished 5-HT data of Feeney, Navratil and Boyeson/. Importantly, Boyeson and Krobert report /13/ that a localized infusion of NE into the cerebellar cortex contralateral, but not ipsilateral, to the SMCX injury, facilitates recovery from hemiplegia. Complimentary reinstatement data have recently been published /12/. Similarly, microinfusion of the
$\alpha_{1}$-NA antagonist, phenoxybenzamine, into the cerebellar cortex contralateral, but not ipsilateral, to a SMCX ablation reinstates deficits in animals recovered from SMCX ablation /12/.

In summary, the results of the experiments reviewed above indicate that NA plays a critical role in spontaneous recovery and the AMPH/SRE enhancement of recovery. Lastly, the integrity of $\alpha_{1}$-NA receptors is important for recovery of function after cortical injury and in maintaining that recovery.

\section{ENDURING RECOVERY MAINTAINED BY ADRENAL AUTOGRAFTS}

While the short term NA pharmacological treatment combined with SRE produces an enduring enhancement of recovery from some symptoms of cortical injury there may be other serious deficits remaining. One interesting symptom of unilateral frontal cortex ablation in the cat is the permanent and total loss of tactile and proprioceptive placing reflexes in the contralateral forelimb. As discussed above, after frontal cortex ablation in the cat tactile and proprioceptive placing can be temporarily restored by administration of AMPH, which we termed a "drug-dependent" functional recovery. There is some evidence for similar drug-dependent effects on the very disabling symptom of aphasia /36/ in a chronic stroke patient. In such cases long term pharmacological treatment may result in undesirable effects and tolerance. Therefore, we tested the approach that has been used by others, transplanting adrenal medulla chromaffin cells into brain after frontal ablation $/ 63 /$ as an endogenous source of increased NE in the CNS.

Large unilateral frontal motor cortex ablations were performed in five cats. Reconstruction of the lesions indicated that they included, in all cats, removal of the anterior and posterior sigmoid and coronal gyri and extended into the underlying white matter without infringing upon the caudate nucleus. The most ventral aspects of the rostral gyrus proreus and the ventral half of the cingulate gyrus were spared medially. In the two cats that received "late grafts", there was additional minor damage to the anterior portions of the anterior ectosylvian and suprasylvian gyri and the lateral and sylvian gyri. 
These lesions produced a complete loss of tactile placing and very severe BW deficits. Two time intervals between cortex ablations and transplantation were used because work in the rat demonstrated that a lesion-graft time interval enhanced graft survival. However, in the cat we could only guess at the optimal interval. Therefore, two cats were prepared with a 12 day interval between ablation and transplant, referred to as "early" grafts. Two other cats with a 21 day interval are referred to as "late" grafts. One cat had a unilateral frontal cortex ablation and 21 days later the right adrenal gland removed but not grafted. This animal served as a control for some unanticipated effect of adrenalectomy alone on recovery from frontal cortex ablation.

For grafting, the animals were reanesthetized and the cortical wound reexposed. The right adrenal gland was isolated, its vasculature ligated and the entire gland removed and placed in sterile, lactated Ringer's solution. Under an operating microscope the medullary tissue was separated from the adrenal cortex and cut into small pieces $\left(0.5-2.0 \mathrm{~mm}^{3}\right)$. In the cortical wound, gelfoam was gently retracted and the field covered with sterile saline-moistened gauze. The adrenal medullary pieces were picked up with a glass pipette and one or two pieces placed into four sites on the floor of the cortical cavity in the most lateral, medial, rostral and caudal areas of the ablation.

The survival of the grafts was determined by processing alternate sections for catecholamine histochemistry 7-10 months after transplantation. The data indicated that some chromaffin cells survived in the grafted wound cavity of all four cats with transplants. It appeared that the 21 day late graft interval was much more favorable for survival of the transplanted chromaffin tissue. In one of the two early grafted animals there were two catecholamine fluorescing sites. In the other early graft cat seven fluorescing sites were observed. However, all but one of these sites were encompassed by macrophage activity and encapsulated in scar tissue. The two late grafted cats had 13 and 24 fluorescent cell clusters which appeared integrated with the host parenchyma and had little or no macrophage activity. The ten month survival of the graft in the late graft animals is impressive, for the tactile placing data clearly indicate that the late grafts were physiologically active in secreting catecholamines.

As illustrated in Figure 1, the effects of late grafting on restoration of tactile placing was very dramatic. Only after late grafting were any tactile placing responses observed in the affected forelimb of these cats with unilateral frontal ablations. Following cortical ablation, perfect responding (0 SEMs) was totally abolished contralateral to the lesion in all animals. After late grafting, tactile placing was partially ( 7 of 10 placing responses) and occasionally completely restored (10 of 10$)$ in both cats for the 7-10 month duration of the study. In our experience with many other adult cats with comparable unilateral lesions, there has been no spontaneous recovery; this includes an animal which has been followed for more than seven years. Beamwalking recovery in late graft animals was also facilitated, being equivalent to that observed after three doses of AMPH combined with SRE. The late graft cats had returned to their baseline preablation BW performance level by 24 days after grafting. The data from the early graft animals were inconclusive. The "ablation with adrenalectomy" control animal showed a recovery rate similar to that of cats with similar ablations, which returned to preablation baseline BW scores at 156 days after grafting. We interpreted the late transplants as acting similarly to "endogenous minipumps", slowly releasing catecholamines, and perhaps other important neurotransmitters, for the 7-10 month duration of the experiment.

This grafting of adrenal chromaffin cells into cortical wound cavities may be relevant to late therapy for stroke symptoms. In six carefully studied aphasia patients, ten treatment sessions at four-day intervals of AMPH (10-15 mg administered orally) followed in 30 minutes by one hour of speech therapy showed an acceleration of the expected rate of recovery $/ 67 /$. At three months poststroke all of these patients obtained measured recovery from aphasia markedly exceeding their six month predicted recovery score (based on a mathematical model and objective aphasia testing). Additionally, in a double-blind case study, treatment with $15 \mathrm{mg}$ of orally administered AMPH to a 53 year-old patient with aphasia and hemiplegia 1.5 years after stroke transiently improved several measures of language, sensory and motor 
performance $/ 36 /$. However, these improvements in performance were observed only during the period of overt drug action. If replicated and extended by additional research, such cases of drug dependent symptom alleviation could be amenable to chromaffin cell autografts, perhaps even years following stroke or TBI.

\section{FUNCTIONAL RECOVERY AND ALLEVIATION OF REMOTE FUNCTIONAL DEPRESSION (DIASCHISIS)}

The mechanism(s) of the NA/SRE effect or even the basis of spontaneous recovery is at present unclear. There are no detectable effects of AMPH/SRE treatment on the volume of the cortical injury $/ 27 /$. It has been proposed $/ 19 /$ that some symptoms of brain injury result from a remote functional depression (RFD), a concept formulated to replace the older theory of diaschisis /19/. The RFD can be manifest in depressed neuronal metabolism. It is widely accepted that some types of selective neuronal death distant from an infarct or TBI site can be a result of "excitotoxicity"/1/. This is attributed to a massive release of excitatory amino acid (EAA) neurotransmitters at the injury site and/or in distant areas transynaptically mediated by axons originating from the direct injury $/ 57 /$. It was proposed that excessive but sublethal EAA receptor activation may be the cellular basis of RFD. According to this soft excitotoxicity hypothesis /19/, focal cortical injury results in widespread metabolic depression from the disruption of ionic homeostasis in neurons injured, but not killed, by exposure to the massive amounts of EAAs.

After SMCX ablation or TBI we reported a reduced local cerebral metabolic rate for glucose utilization (LCMRGlu), reduced oxidative metabolism indicated by weaker histochemical stain intensity for cytochrome oxidase (a mitochondrial enzyme), and a different pattern of lowered intensity of histochemical staining for the oxidative enzyme alpha-glycerophosphate dehydrogenase $/ 19,26 /$. Similar to the behavioral recovery data presented above, the metabolic depression is normalized by the AMPH/SRE treatment $/ 26 /$. From that and other data we hypothesized that enhancement of recovery results from the alleviation of injury-induced metabolic depression of structures remote from, but connected to, the site of injury $/ 19,26 /$. Additionally, the administration of haloperidol worsens the metabolic depression and when coadministered with AMPH blocks the normalization of depressed LCMRGlu after SMCX injury $/ 26 /$. Similar effects of AMPH on reduced glucose metabolism after cortical injury have been reported in a recent acute 2-DG investigation using the photochemical infarct model /17/. The authors report a marked depression of the normal pattern of LCMRGlu activation by vibrissae stimulation at two weeks-post infarct. During the period of AMPH action, vibrissae stimulation increased LCMRGlu in cortical areas not activated in untreated infarcted animals /17/

An additional factor that is likely to contribute to RFD is axotomy of the projections of the locus coeruleus to the SMCX by ablation or contusion. The locus coeruleus axonal projections are unusual in that so few cells give rise to axons which bifurcate, and the same neuron can send projections to the ipsilateral SMCX and both cerebellar hemispheres. Because of this unique anatomy of NA forebrain projections, injuring the locus coeruleus axon terminals in SMCX should influence the amount of NA released in areas remote from the injury, such as the cerebellum. To test our hypothesis, we recently used microdialysis in awake behaving rats to measure the spontaneous and AMPH-evoked release of NA in cerebellar cortex 24 hours after SMCX-TBI. Spontaneous NA release was significantly depressed in the cerebellum. There was, however, sufficient NA in stores so that the usual AMPH dose $(2 \mathrm{mg} / \mathrm{kg}$ i.p.) increased release by $522-1088 \%$, which slowly returned to baseline over the 5 hours after injection 144/. The mechanism proposed as a basis for enhanced recovery by AMPH/SRE was "...from an AMPH-evoked increase of norepinephrine within the cerebellum which, in conjugation with afferent feedback (SRE) to cerebellar neurons, produces an enduring use-dependent strengthening of responses to this input" /19: p.121/. The data from this recent in vivo cerebellar microdialysis experiment /44/ confirm one important aspect of the theory.

The observed metabolic disturbances remote from the site of cortical damage, their spontaneous 


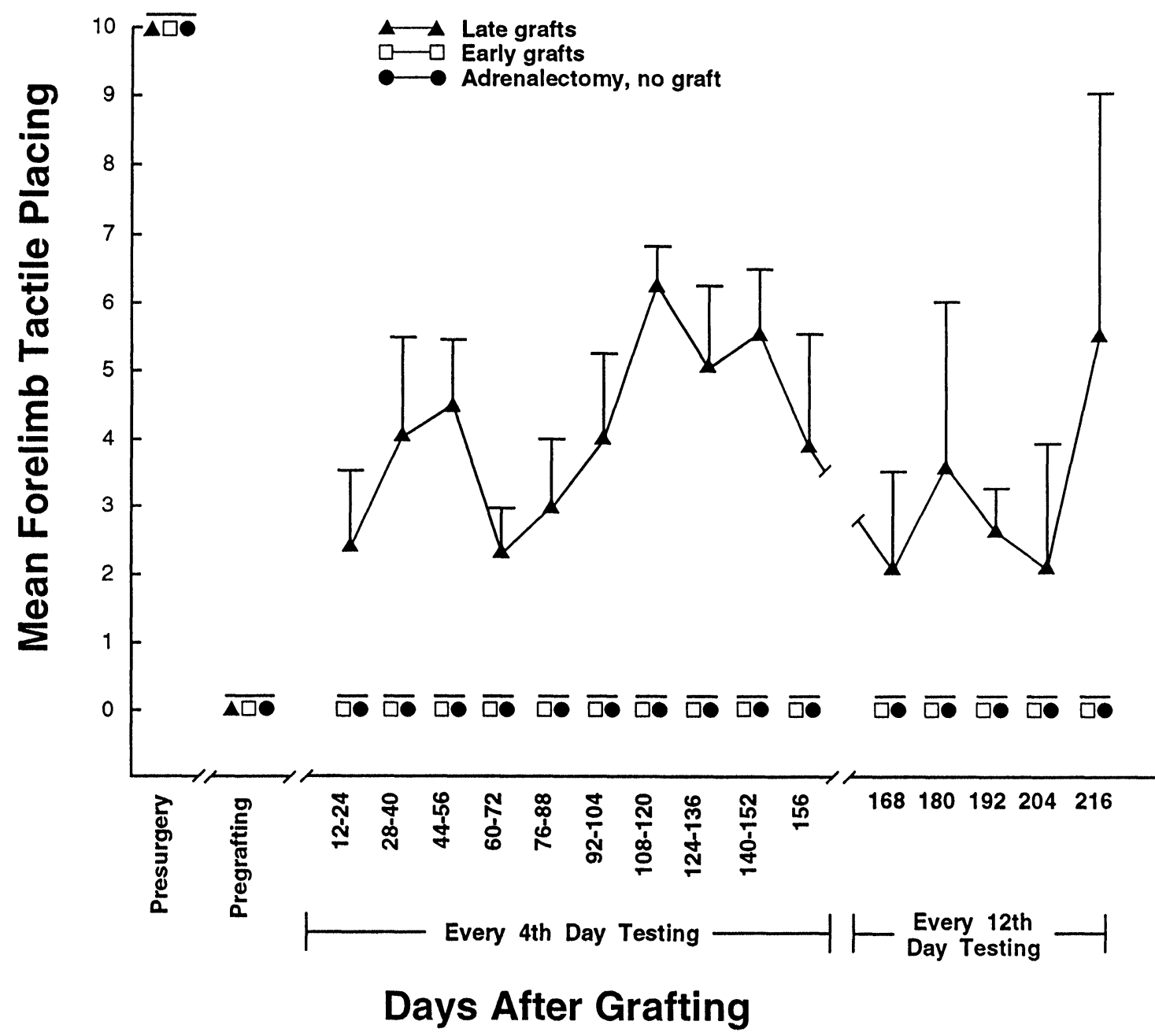

Fig. 1: Mean ( \pm SEM) tactile placing responses in cats before and after large unilateral frontal cortex ablations. From post surgery day 12 , the first post grafting test day, to day 152 after early grafting, each point represents the mean group performance over 4 consecutive test sessions. The results illustrate the perfect performance of all animals prior to cortical injury and the complete loss of responding in all animals after surgery. Previous work has indicated that this total loss of responding is permanent. However, as illustrated in the late graft condition, partial restoration of tactile placing can be produced by transplantation of homologous adrenal medulla cells directly into the cortical wound cavity 21 days following ablations. The adrenalectomy without grafting animal had a unilateral frontal lesion and 21 days later the right adrenal gland was removed. This was performed to control for the possibility that tactile placing might be restored by adrenalectomy alone, without the autograft. The data illustrate the enduring amelioration of a presumed "permanent" deficit after brain damage by grafting an "endogenous catecholamine minipump" into the brain parenchyma. Analyses of the brain tissue of these animals for catecholamine florescence revealed considerably more surviving chromaffin cells in animals with late transplants than in the early graft animals at 7-10 months after surgery. Adapted from Sutton, Hovda and Feeney /63/ with permission. In the original publication there were calculation errors for the last 5 SEMs. With the help of Dr. Sutton, they were recalculated from the raw data. The correct values are presented in this figure. 
dissipation, and the normalizing effect of AMPH treatment provide support for the concept of diaschisis, or remote functional depression. Remote metabolic disturbances and subsequent normalization may contribute to observed behavioral deficits and their spontaneous recovery, respectively. The effect of AMPH/SRE may be to accelerate the resumption of normal metabolic and biochemical processes within neuronal circuits necessary for recovery of some functions after cortical injury.

\section{CONCLUSIONS AND IMPLICATIONS FOR CLINICAL TRIALS}

The data reviewed support the proposed central "enabling" role for NA in spontaneous or treatmentenhanced functional recovery after cortical injury. Enhanced functional recovery after cortical injury by short-term therapy using AMPH, or one of the many other drugs which increase NA synaptic activity, is enduring when combined with SRE. There are several reasons for cautious optimism regarding the clinical relevance of this laboratory discovery that AMPH/SRE promotes recovery of BW in rats with cortical ablation and related studies. The initiation of treatment can be delayed for weeks after injury in the cat. The enhancement of recovery affects several qualitatively different types of cortical injury and subsequent symptoms of cortical injury. Importantly, not all deficits following cortical injury respond to treatment and research is required to determine those symptoms that do respond and what drug/SRE protocols are most effective in promoting recovery.

The enhanced recovery seems more robust in "higher" species. For example, the effect of AMPH/SRE on functional recovery is more dramatic in the cortically injured cat than in rat and perhaps even more robust in human stroke cases. There are statistically significant pilot data from two double blind studies of small samples $(\mathrm{N}=4$ or 5 per group) of carefully selected stroke cases $/ 16,67 /$. In a third double blind study of recovery of stroke patients from hemiplegia, non-significant differences were reported comparing a group of 5 patients given short term AMPH treatment compared to placebo controls $/ 7 /$. However, no period of specific
SRE was scheduled following drug or placebo administration (Dr. S.J. Borucki, personal communication to DMF). This drug or placebo treatment was simply incorporated into the rehabilitation program of the patient. Additionally, random assignment unfortunately resulted in a significant difference in the mean age of the two groups, the average age of the treatment group being 73 compared to 57 for the control group. Lastly, for most patients treatment was not initiated until over a month after their stroke, which Dr. Borucki considered a major factor for their negative findings (personal communication). Nevertheless, the results of motor function testing between groups (The Fugl-Meyer test, the same as successfully used in the earlier studies) showed striking differences which approach significance. This study reinforces the hypothesized importance of SRE scheduled during the period of maximal drug activity.

Future studies of this treatment approach should also consider i.m. or s.c. drug administration to reduce variability of absorption and measurement of blood drug levels since this could account for some of the variance between patients and may correlate with response to treatment. Additionally, when using small samples, stratified random sampling should be considered instead of simple random assignment to match the groups on such important variables as age. Because such small samples also usually do not meet the criteria required for parametric statistical comparisons, non-parametric statistical analyses may be more appropriate. Finally, in our laboratory investigations in the rat, we found that different AMPH dosages are required depending upon the hemisphere injured /43/. With the greater cerebral lateralization in human beings, mixing left and right hemisphere stroke cases in a group may also increase the variance. With a sufficient sample size in studies of stroke patients this factor could be isolated and separately examined. Clearly, these data generated in different laboratories warrant continued research to develop a therapy to promote functional recovery after cortical damage.

JOURNAL OF NEURAL TRANSPLANTATION \& PLASTICITY 


\section{ACKNOWLEDGEMENTS}

We thank Drs. Goldstein and Boyeson for preprints of their most recent work to help this review to be as current as possible and A.E. Walker for his helpful comments on an early draft of this manuscript. We also wish to thank and acknowledge Helen M. Bramlett for her work on constructing the tables and helpful assistance in the preliminary work on this manuscript.

\section{REFERENCES}

1. Albers GW, Goldberg MP, Choi DW. N-Methyl-daspartate antagonists: ready for clinical trial in brain ischemia? Ann Neurology 1989; 25: 398-403.

2. Amassian VE, Ross $\mathrm{R}$, Wertenbaker $\mathrm{C}$, Weiner $\mathrm{H}$. Cerebellothalamocortical interrelations in contact placing and other movements in cats. In: Frigyesi T, Rinvik E, Yahr MD, eds, Corticothalamic Projections and Sensorimotor Activities. New York: Raven Press, $1972 ; 395$.

3. Azzaro AJ, Rutledge CDO. Selectivity of release of norepinephrine, dopamine, and 5-hydroxytryptamine by amphetamine in various brain regions of the rat brain. Biochem Pharmacol 1973; 22: 2801-2813.

4. Barela PB, Weisend MP, Feeney DM. Yohimbine facilitates beam-walking recovery in moderately but not severely diabled rats after cortical contusion, Submitted.

5. Beani L, Tanganelli $\mathrm{S}$, Antonelli $\mathrm{T}$, Bianchi $\mathrm{C}$. Noradrenergic modulation of cortical acetylcholine release is both direct and gamma-aminobutyric acidmediated. J Pharmacol Exp Therapeut 1986; 236: 230.

6. Bogen JE, Suzuki M, Campbell B. Paw contact placing in the hypothalamic cat given caffeine. J Neurobiol 1975; 6: 125

7. Borucki SJ, Langberg J, Reding M. The effect of dextroamphetamine on motor recovery after stroke. Neurology 1992; 42 (Suppl 3): 329.

8. Boyeson MG, Callister TR, Cavazos JE. The biochemical and behavioral effects of sensorimotor cortex injury in rats pretreated with the noradrenergic neurotoxin DSP-4. Behav Neurosci 1992; 106: 964973.

9. Boyeson MG, Feeney DM. Adverse effects of catecholaminergic agonists and antagonists on recovery of locomotor ability following unilateral cerebellar ablations. Restorative Neurol Neurosci 1991; 3: 227-233.

10. Boyeson MG, Feeney DM. Intraventricular norepinephrine facilitates motor recovery following sensorimotor cortex injury. Pharmacol Biochem Behav 1990; 35: 497-501.
11. Boyeson MG, Harmon RL. Effects of trazadone and desipramine on motor recovery in brain injured rats. Am J Phys Med Rehab 1993, in press.

12. Boyeson MG, Krobert KA, Scherer PJ, Grade CM. Reinstatement of motor deficits in recovered brain injured animals. Restorative Neurol Neurosci 1993; 5: 283-290

13. Boyeson MG, Krobert KA. Cerebellar norepinephrine infusions facilitate recovery after sensorimotor cortex injury. Brain Res Bull 1992; 29: 435-439.

14. Cole JR, Cope DN, Cervelli L. Rehabilitation of the severely brain-injured patient: A community-based, low-cost model program. Arch Phys Med Rehabil $1985 ; 66.38-40$

15. Cools AR. Basic considerations of the role of concertedly working dopaminergic, GABA-ergic, cholinergic and serotonergic mechanisms within the neostriatum and nucleus accumbens in locomotor activity, stereotyped gnawing, turning and dyskinetic activities. In: Ellinwood EH, Kilbey MM, eds, Cocaine and Other Stimulants. New York: Plenum Press 1977; 97-141.

16. Crisostomo EA, Duncan PW, Propst M, Dawson DV, Davis JN. Evidence that amphetamine with physical therapy promotes recovery of motor function in stroke patients. Ann Neurol 1988; 23: 94-97.

17. Dietrich WD, Alonso O, Busto R, Ginsberg MD. The effect of amphetamine on functional brain activation in normal and post-infarcted rat. Stroke 1990; 21 (Suppl 3): $147-150$

18. Dunbar G. D-Amphetamine attenuates learning and motor deficits following cortical injury in rats Neurosci Abstr 1989; 19: 132.

19. Feeney DM. Pharmacological modulation of recovery after brain injury: A reconsideration of diaschisis. J Neurol Rehabil 1991; 5: 113-128.

20. Feeney DM, Boyeson MG, Linn RT, Murray HM, Dail WG. Responses to cortical injury: I. Methodology and local effects of contusions in the rat. Brain Res 1981; 211: 67-77.

21. Feeney DM, Gonzalez A, Law WA. Amphetamine, haloperidol and experience interact to affect rate of recovery after motor cortex injury. Science 1982; 217 : 855-857.

22. Feeney DM, Hovda DA. Amphetamine and apomorphine restore tactile placing after motor cortex injury in the cat. Psychopharmacology 1983; 79: 67.

23. Feeney DM, Hovda DA. Reinstatement of binocular depth perception by amphetamine and visual experience after visual cortex ablation. Brain Res 1985; 342: 352-356.

24. Feeney DM, Sutton RL. Pharmacotherapy for recovery of function after brain injury. CRC Crit Rev Neurobiol 1987; 3: 135-197.

25. Feeney DM, Sutton RL. Catecholamines and recovery of function after brain damage. In: Sabel B, Stein D, eds, Pharmaocological Approaches to the Treatment of 
Brain and Spinal Cord Injury. New York: Plenum Publishing Co., 1988; 121-142.

26. Feeney DM, Sutton RL, Boyeson MG, Hovda DA, Dail WG. The locus coeruleus and cerebral metabolism: Recovery of function after cortical injury. Physiol Psychol 1985; 13: 197-203.

27. Feeney DM, Sutton RL, Weisend MP, Eagan KP. Effect of delayed amphetamine treatment on secondary pathology after cortical contusion. Soc Neurosci Abstrs 1990; 16: 779.

28. Feeney DM, Weisend MP, Krobert KA, Queen S. Feasibility study of pharmacological treatment to reduce morbidity and mortality after brain injury. Annual Report, Contract No. DAMD17-86-C-6144, University of New Mexico, May 1, 1987; NTIS, ADA $183526 \mathrm{f}$.

29. Feeney DM, Westerberg VS. Norepinephrine and brain damage: Alpha noredrenergic pharmacology alters functional recovery after cortical trauma. Can J Psychol 1990; 44: 233-252.

30. Fuxe K, Ungerstedt U. Histochemical, biochemical and function studies on central monoamine neurons after acute and chronic amphetamine adminstration. In: Costa E, Garattini S, eds, Amphetamine and Related compounds. New York: Raven Press, 1970; 257-288.

31. Goldstein LB. Pharmacologic modulation of recovery after stroke: Clinical data. J Neurol Rehabil 1991; 5: 129-140.

32. Goldstein LB, Coviello A. Post-lesion administration of the NMDA receptor antagonist MK-801 does not impair motor recovery after unilateral sensorimotor cortex injury in the rat. Brain Res 1992; 580: 129-136.

33. Goldstein LB, Davis JN. Post-lesion practice and amphetamine-facilitated recovery of beam-walking in the rat. Behav Neurosci 1990; 104: 318-325.

34. Goldstein LB, Davis JN. Clonidine impairs recovery of beam-walking after a sensorimotor cortex lesion in the rat. Brain Res 1990; 508: 305-309.

35. Goldstein LB, Poe HV, Davis JN. An animal model of recovery of function after stroke: facilatation of recveory by an alpha ${ }_{2}$-adrenergic antagonist. Ann Neurol 1989; 26: 157.

36. Homan R, Panksepp J, McSweeney J, et al. DAmphetamine effects on language and motor behavior in a chronic stroke patient. Soc Neurosci Absts 1990; 16: 439.

37. Hovda DA, Feeney DM. Amphetamine and experience promote recovery of function after motor cortex injury in the cat. Brain Res 1984; 298: 358-361.

38. Hurwitz BE, Dietrich WD, McCabe PM, Alonso O, Watson BD, Ginsberg MD, Schneiderman N. Amphetamine promotes recovery from sensory-motor integration deficit after thrombotic infarction of the primary somatosensory rat cortex. Stroke 1991; 22 (5): 648-654.

39. Interagency Head Injury Task Force Report, 1989. Department of Health and Human Services, Public
Health Service, National Institutes of Health, National Institute of Neurological Disorders and Stroke.

40. Jonason KR, Lauber SM, Robbins MJ, Meyer PM, Meyer DR. Effects of amphetamine upon relearning patterns and black-white discriminations following neocortical lesions in rats. J Comp Physiol Psychol 1970; $73: 47$

41. Kannel WB, Wolf PA. Epidemiology of cerebrovascular disease. In: Ross Russel RW, ed, Vascular Disease of the Central Nervous System. Edinburgh: Churchhill Livingston, 1983; 45.

42. Kline AE, Chen M, Tso-Olivas D, Feeney DM. Methylphenidate treatment following ablation induced hemiplegia in rat: Experience during drug action alters effects on recovery of function. Submitted, 1993.

43. Kline AE, Salazar RA, Bustos EA, Feeney DM, Benzel EC. Effects of amphetamine on beam-walk recovery following right or left sensorimotor cortex contusion in rat. Soc Neurosci Abstr 1993; 19: 1878.

44. Krobert KA, Sutton RL, Feeney DM. Spontaneous and amphetamine-evoked release of noradrenaline after cortical contusion: An in-vivo microdialysis study in the rat. J Neurochemistry 1993, in press.

45. Kuczenski R. Biochemical actions of amphetamine and other stimulants. In: Creese I, ed, Stimulants: Neurochemical, Behavioral and Clinical Perspectives. New York: Raven Press, 1983; 31-61.

46. Kuczenski R, Segal DS. Regional norepinephrine response to amphetamine using dialysis: Comparison with caudate dopamine. Synapse 1992; 11: 164-169.

47. L'Heureux R, Dennis T, Curet O, Scatton B. Measurement of endogenous noradrenaline release in the rat cerebral cortex in vivo by transcortical dialysis: effects of drugs affecting noradrenergic transmission. J Neurochem 1986; 46: 1794-1801.

48. MacKenzie EJ, Shapiro S, Siegel JH. The economic impact of traumatic injuries: One-year treatmentrelated expenditures. JAMA 1988; 260: 3290-3296.

49. Maling HM, Acheson GH. Righting and other postural activity in low-decerebrate and spinal cats after Damphetamine. J Neurophsyiol 1946; 9: 379-386.

50. Meyer PM, Horel JA, Meyer DR. Effects of D,Lamphetamine upon placing responses in neodecorticate cats. J Comp Physiol Psychol 1963; 56: 402-404.

51. Niddam R, ARbilla $S$, Scatton $B$, Dennis $T$, Langer SZ. Amphetamine induced release of endogenous dopamine in vitro is not reduced following pretreatment with reserpine. Naunyn-Schmiedeberg's Arch Pharmacol 1985; 329: 123-127.

52. Ogren SO, Archer T, Johansson C. Evidence for a selective brain noradrenergic involvement in the locomotor stimulant effects of amphetamine in the rat. Neurosci Lett 1983; 43: 327-331.

53. Ritchie GD, Meyer PM, Meyer DR. Residual spatial vision of cats with lesions of the visual cortex. Exp Neurol 1976; 53: 227. 
54. Robins $M$, Baum HM. Incidence, in The National Survey of Stroke. Weinfeld FD, ed, Stroke (suppl) 1981; 12: 145.

55. Salo AA, Feeney DM. Reduction of morbidity, mortality, and lesion size in rat model of cerebral infarction with amphetamine. Soc Neurosci Abst 1987; 13: 1268

56. Scheel-Kruger J. Comparative studies of various amphetamine analogues demonstrating different interactions with the metabolism of the catecholamines in the brain. Eur J Pharmacol 1971; 14: 47-60.

57. Schwob JE, Fuller T, Price JL, Olney JW. Widespread patterns of neuronal damage following systemic or intracerebral injections of kainic acid: a histological study. Neuroscience 1980; 5: 991-1014.

58. The Silent Epidemic. Rehab Brief 1988; 9 (4): 1-4.

59. Sloviter RS, Drust FG, Conner JD. Evidence that serotonin mediates some behavioral effects of amphetamine. J Pharmacol Exp Therap 1978; 206: 348-352.

60. Sutton RL, Feeney DM. Noradrenergic pharmacotherapy and functional recovery after cortical injury. In: Illis LS, ed, Neurological Rehabilitation. Oxford, England: Backwell Publishing Co., in press.

61. Sutton RL, Feeney DM. Alpha-noradrenergic agonists and antagonists affect recovery and maintenance of beam-walking ability after sensorimotor cortex ablation in the rat. Res Neurol Neurosci 1992; 4: 1-11.

62. Sutton RL, Hovda DA, Feeney DM. Amphetamine accelerates recovery of locomotor function following bilateral frontal cortex ablation in cats. Behav Neurosci 1989; 103 (4): 837-841.

63. Sutton RL, Hovda DA, Feeney DM. Intracerebral chromaffin cell autografts accelerate functional recovery in adult cats with unilateral frontal cortex ablation. Brain Dysfunction. 1989; 2: 201-209.

64. Sutton RL, Weaver MS, Feeney DM. Drug-induced modifications of behavioral recovery following cortical trauma. J Head Trauma Rehab 1987; 2 (4): 50-58.

65. Trunkey D. Neural trauma from the point of view of the general surgeon. In: Dacey RG, Winn HR, Rimmel RW, Jane JA, eds, Trauma of the Central Nervous System. New York: Raven Press, 1985; 9.

66. Walker AE, Robins M, Weinfield. The National Survey of Stroke: Clinical findings. Stroke (Suppl) 1981; 12: 13.

67. Walker-Batson D, Unwin H, Curtis S, Allen E, Wood M, Smith P, Devous MD, Reynolds S, Greenlee RG. Use of amphetamine in the treatment of aphasia. Restorative Neurol Neurosci 1992; 4: 47-50.

\section{NOTE ADDED IN PROOF}

Studies of precursors for DA or NA, L-DOPA and L-DOPS respectively, have shown that L-DOPS but not L-DOPA enhanced recovery of beam walking after unilateral SMCX ablation in rat (Nishino $\mathrm{K}$, Onyu $\mathrm{H}$, Masayoshi M. Sensorimotor cortex ablation model. Functional Neurosurgery 1991; 30: 116-124. The text is in Japanese but the abstract and figure captions are in English. Additionally, these authors briefly presented some of the data in Neuroscience Abstracts, 1991; 17 150). We have unpublished data also indicating the lack of any effect on recovery from hemiplegia by L-DOPA. Their observations warrant replication and extension, because of the potential usefulness of L-DOPS, which has weaker cardiovascular side effects than AMPH, but also promotes recovery after brain damage.

Interestingly, a recent study reported that a single dose of AMPH, apparently administered without SRE, significantly slowed beam walk recovery in rats with photochemical induced infarcts (Bjelk B, Brown A, Sabouri S, Fuxe K. Beam walking without aversive stimuli as a tool to record motor recovery after photochemical induced unilateral lesions of the sensorymotor cortex. Training effect contra d-amphetamine treatment. Neuroscience Abstracts 1993; 19: 1653). The report of AMPH slowing motor recovery in this model is quite surprising since others, using the same stroke model $/ 17,38 /$, report AMPH significantly improves other functional and physiological outcome measures. For example, Hurwitz et al. $/ 38 /$ using this photochemical infarct model and a sensorimotor outcome measure, note that 4.0 not $2.0 \mathrm{mg} / \mathrm{kg}$ of AMPH, the dose used in this recent study, significantly enhances recovery. We have seen a similar requirement for higher or multiple AMPH doses to enhance recovery in an embolic stroke model. We await a more detailed publication of this important experiment because the data conflict with so many other studies. If replicable and not attributable to dosage or lack of SRE, the observation may indicate limitations of this therapeutic approach. 

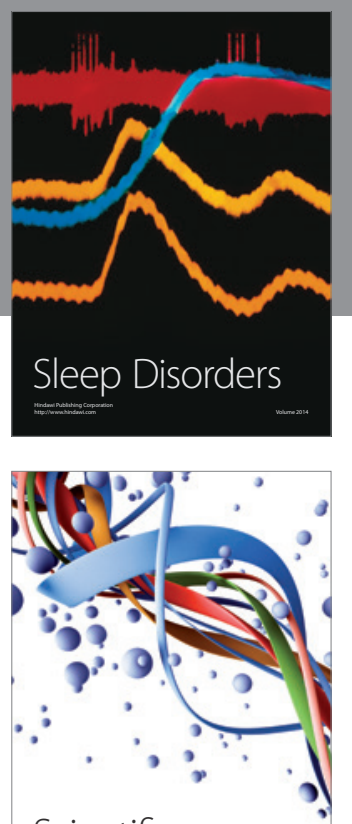

Scientifica
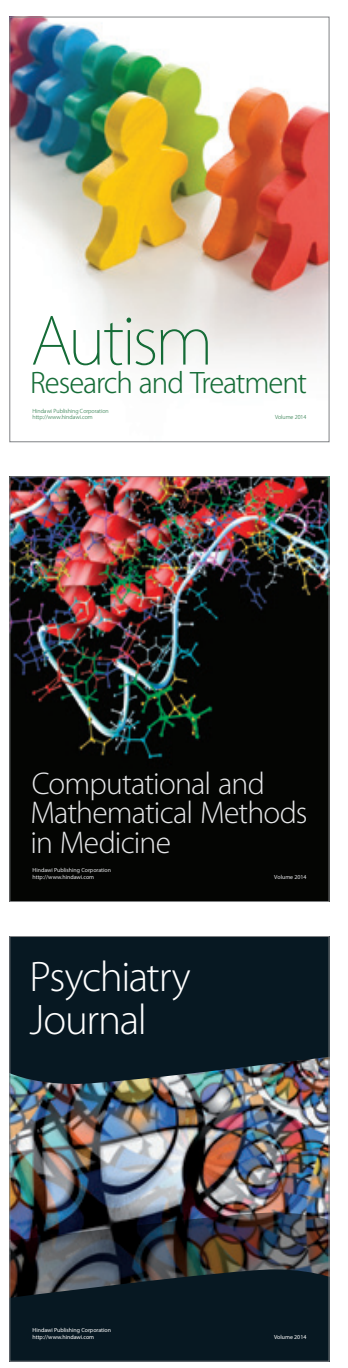
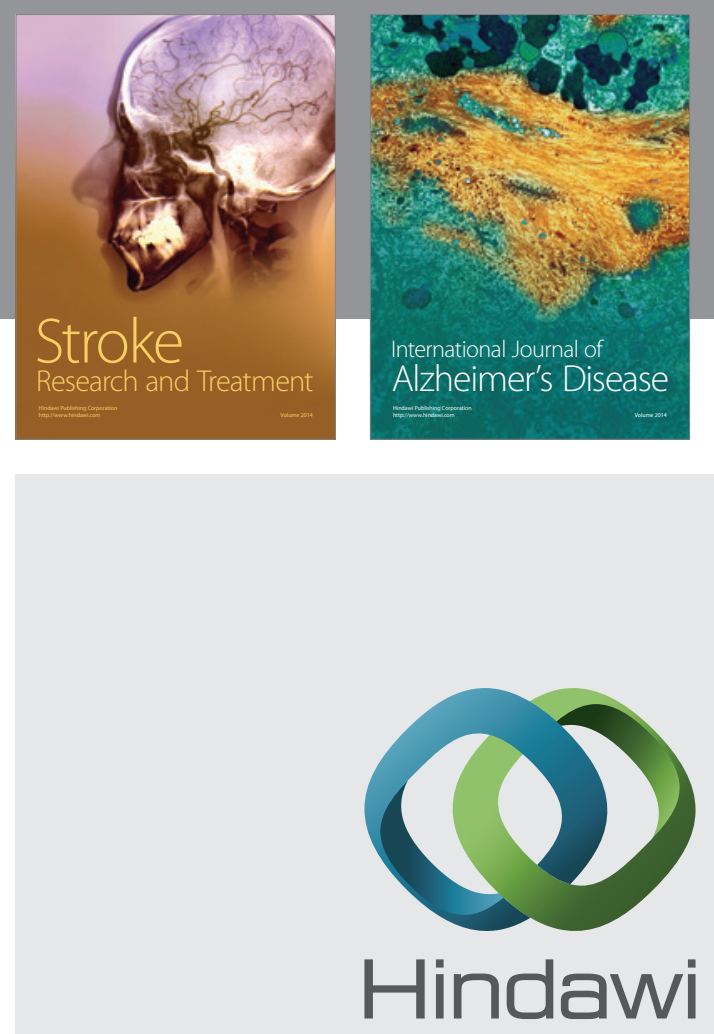

Submit your manuscripts at

http://www.hindawi.com
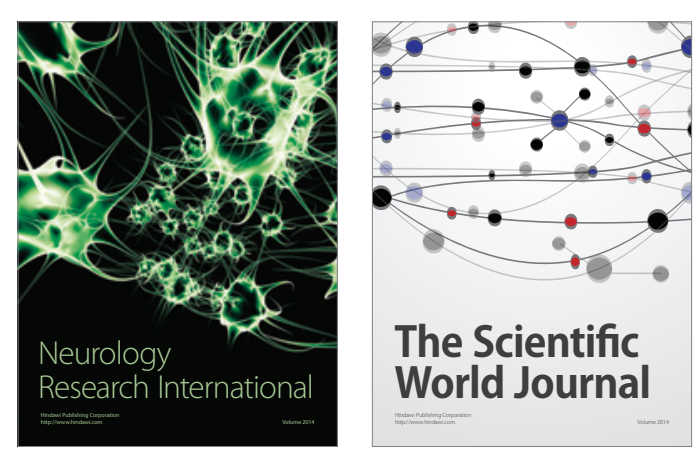

The Scientific World Journal

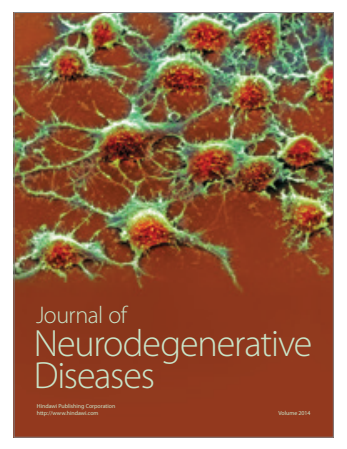

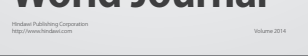

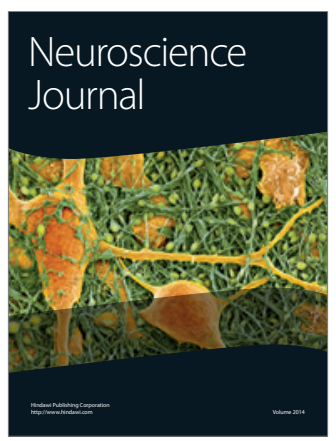

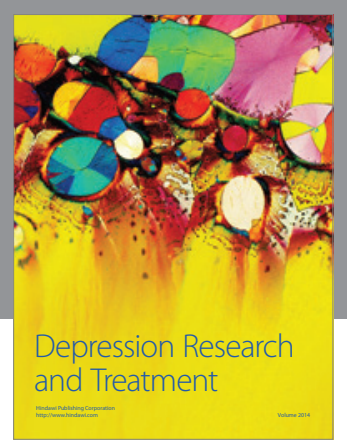
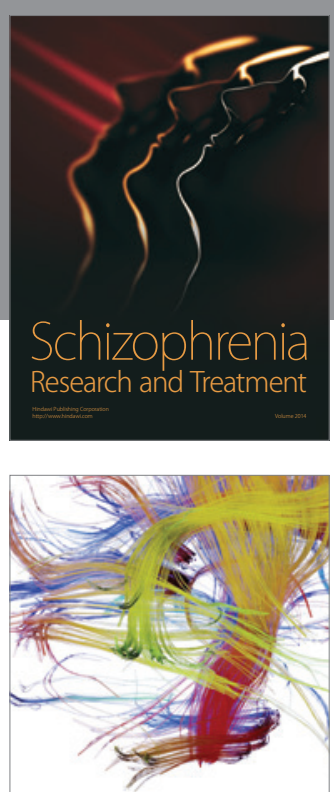

Brain Science

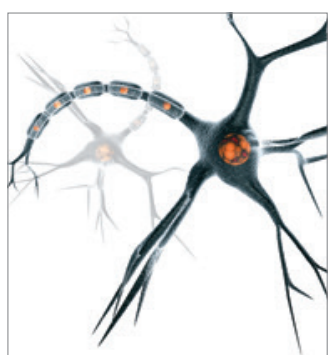

Neural Plasticity
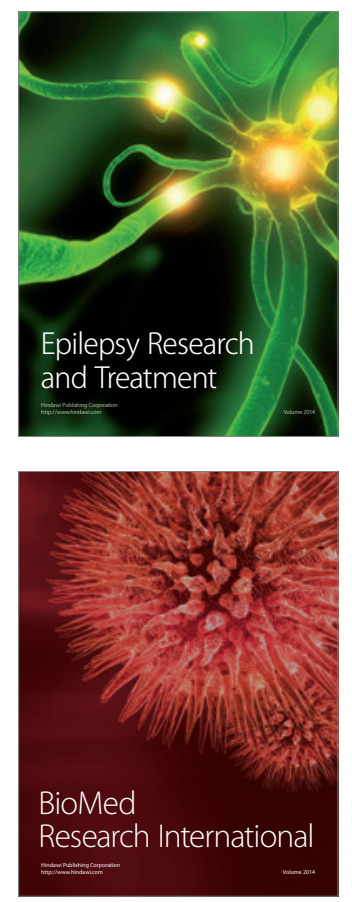

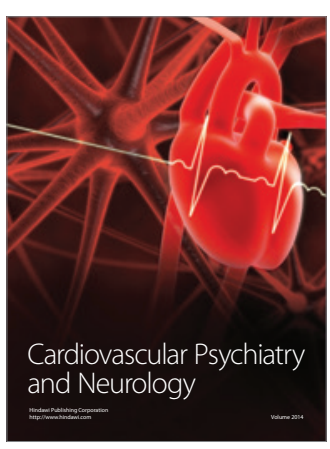

Parkinson's

Disease
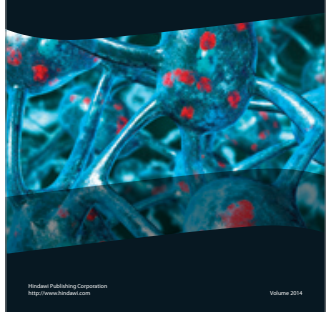